\title{
A Study on Present Situation of Jiujiang County’s Commercial Network
}

\author{
Shenghui YAO ${ }^{1}$, Lifen XIE ${ }^{2}$
}

1) Department of Marketing, Electronic Commerce Institute, Jiujiang University, China (yshxlf@163.com)

2) Department of International Trade, Economics and Management Institute, Jiujiang University, China (xielifen2003@ 163.com)

\begin{abstract}
The paper does the correlevant analysis on the partial macroeconomic indicators and the commercial network index of the county-level cities, based on the survey data of the county-level cities' commercial network in Jiujiang. The data analysis shows that there are some correlations between the commercial network index of the county-level cities and some macroeconomic indicators, which lays the theoretical foundation for the further research.
\end{abstract}

Keywords - county-level cities, commercial network Present Situation, exploratory research

\section{九江市县级城市商业网点现状探索性研究}

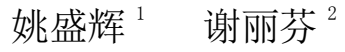 \\ 1）九江学院电子商务学院市场营销教研室, 中国 \\ 2) 九江学院经济与管理学院国际贸易教研室, 中国
}

摘 要 本文以九江市县级城市商业网点的调查数据为基础, 对县级城市部分宏观经济指标与县级城市商业网点指标进行了相关 分析研究。通过对数据研究分析表明, 县级城市商业网点与部分宏观经济指标间确实存在一定的相关性, 为进一步进行分析研究奠定 了理论基础。

关键词 县级城市, 商业网点现状, 探索性研究

1. 引言

县级城市是我国城市体系中的初级城市, 是连接地级 城市和农村乡镇的重要纽带, 总结县级城市商业网点现状 规律, 对今后开展县级城市商业网点规划相关工作起到理 论参考作用。当前国内外关于城市商业网点的研究文献, 大都集中在大型城市商业网点规划方向, 对县级城市商业 网点发展现状的研究较少, 而进一步研究到县级城市商业 网点与经济对应关系的理论成果更是少之又少, 本文旨在 探究县级城市商业网点现状与经济发展相关性的一般规 律, 从而丰富了县级城市商业网点研究的理论成果, 为县 级城市商业经济发展提供理论基础。

\section{2.城市商业网点研究述评}

国内关于商业网点为主题的研究主要参考克利斯泰勒 （1933）提出的 “中心地理论” 思想, 虽然现实中克利斯 泰勒提出的假设条件很难满足, 但不可否认其在区域规划
中, 可以起到合理地布局区域的公共服务设施和其它经济 和社会职能的指导作用。除了克利斯泰勒的 “中心地理论” 外, 还有德国地理学家沃尔特克里斯 (1933)、廖什、泰勒 （1939）创立的区位理论; 麦肯齐（1933）、哈里斯和乌尔 曼（1945）创立的 “城市多核理论”; 英国经济学家刘易斯 （1954）阐述的 “二元经济结构” 等一系列的经典理论, 形成了投入产出模型、线性规划模型、区域空间均衡模型、 区域经济增长模型、环境影响模型、动态城市模型、城市 体系的一般均衡模型、分散化的城市理论模型等等。而布 赖恩 - 贝里 (1973) 用数理统计方法对中心地学说进行了许 多实证性研究, 成为了城市系统研究的一个重要转折点, 他把城市人口分布与服务中心的等级联系起来, 为此后的 学者开始从研究城市零售商业的空间布局规律提供了更加 微观的视角。

国外对城市商业网点的研究与实践工作开展已有近百 年的历史, 经历了从宏观到微观的发展过程, 值得我们借 
鉴学习。但是, 我国幅员辽阔特别是区域间的经济发展不 均衡, 要求我们要结合具体区域经济特征对研究对象开展 科学的、有针对的分析, 这样才能更好地指导商业网点规 划的实践工作。方元平（2007）撰文指出：虽然国内城市 商业区位研究已取得显著成就, 但与国外比较, 还存在中观 层面和微观层面的研究关注不足, 研究不够系统, 缺少相对 应理论研究。[8]

\section{3.城市商业网点现状研究方法}

带领 12 批次 120 人次对九江市 9 个县级城市城区规划 范围内的商业网点布局情况进行了全面调查; 并实地走访 了 9 个县级城市的多个政府事业行政单位, 获取相关城市 的统计数据和资料, 完全掌握 9 个县级城市商业网点现状 数据。整理各个县级城市社会经济指标, 分析了近五年的 各个县级城市的经济环境, 通过现有的县级城市商业网点 数据, 从商业网点总数量、网点营业面积和从业人员数量 三个方面描述, 展示各个县级城市的商业网点发展现状。 在完成九江市 9 个县级城市（星子县、湖口县、德安县、 共青城市、彭泽县、都昌县、永修县、武宁县、修水县) 商业网点现状调查的基础上, 对九江市 9 个县级城市商业 网点现状进行研究和分析, 对城市商业网点业态结构和网 点数量现状描述 (因具体原因数据没有公开), 并在此基础 上, 结合各个城市的经济发展水平进行分析。

根据各个县级城市的经济指标和商业网点指标, 运用 双相关方法, 应用 SPSS20.0 软件, 进行数据分析, 探寻经 济数据与网点数据之间的相关性。商业发展指标以商业网 点数量、面积和从业人员数量三个方面进行分析; 社会经 济指标以 GDP、城区人口等经济数据入手进行分析。

\section{4.城市商业网点规划研究数据分析}

\section{1 县级人口数量指标与商业网点相关指标关系分析}

通过 SPSS20. 0 软件对全县人口和商业网点总数、网点 总面积、从业人员数、零售业网点个数、零售营业面积、 零售从业人员数、批发网点数、批发营业面积、批发从业 人员数指标进行 Pearson 双相关分析, 得到如下运行结果。
表 1 全县人口指标与商业网点指标相关分析结果表

\begin{tabular}{|c|c|c|c|c|c|c|c|c|c|c|c|}
\hline & & 全 & 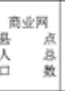 & 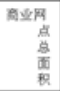 & 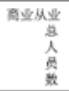 & 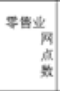 & 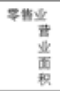 & 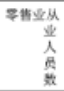 & 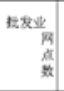 & 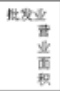 & 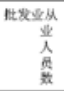 \\
\hline \multirow{3}{*}{ 全县人口 (万人) } & $\begin{array}{r}\text { Pearson } \\
\text { 相 } \\
\text { 荦 }\end{array}$ & 1 & $.721^{\circ}$ & .168 & .288 & $.728^{\circ}$ & $.843^{* *}$ & $.750^{\circ}$ & $.687 \%$ & $.674^{\circ}$ & $.690^{\circ}$ \\
\hline & 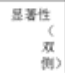 & & .028 & .665 & .452 & .026 & .004 & .018 & .041 & .046 & .044 \\
\hline & $\mathrm{N}$ & 9 & 9 & 9 & 9 & 9 & 9 & 9 & 9 & 9 & 9 \\
\hline \multirow{3}{*}{ 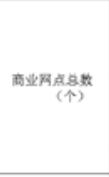 } & $\begin{array}{r}\text { Pearson } \\
\text { 相 } \\
\text { 蒮 } \\
\end{array}$ & .721 & 1 & $A 72$ & .096 & $975 * *$ & $941^{*}$ & $964 "=$ & .386 & $A 28$ & $A 58$ \\
\hline & 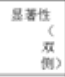 & .028 & & .199 & .807 & .000 & .000 & .000 & 304 & .251 & .215 \\
\hline & $\mathrm{N}$ & 9 & 9 & 9 & 9 & 9 & 9 & 9 & 9 & 9 & 9 \\
\hline \multirow{3}{*}{ 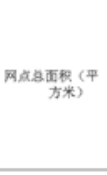 } & $\begin{array}{r}\text { Pearson } \\
\text { 相 } \\
\text { 被 }\end{array}$ & .168 & 472 & 1 & .602 & .533 & 377 & .496 & .168 & .185 & .270 \\
\hline & 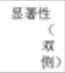 & .665 & .199 & & .087 & .139 & .317 & .174 & .666 & .633 & $A 82$ \\
\hline & $\mathrm{N}$ & 9 & 9 & 9 & 9 & 9 & 9 & 9 & 9 & 9 & 9 \\
\hline \multirow{3}{*}{ 从业总人周 ( } & $\begin{array}{r}\text { Pearson } \\
\text { 相 } \\
\text { 荦 } \\
\end{array}$ & .288 & $.06 \%$ & .602 & 1 & .124 & .151 & .168 & .538 & 488 & .522 \\
\hline & 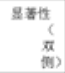 & .452 & .807 & .087 & & .751 & .68 & .665 & .135 & .183 & .149 \\
\hline & $\mathrm{N}$ & 9 & 9 & 9 & 9 & 9 & 9 & 9 & 9 & 9 & 9 \\
\hline \multirow{3}{*}{ 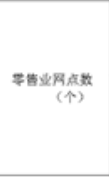 } & $\begin{array}{r}\text { Pearson } \\
\text { 相 } \\
\text { 堂 } \\
\end{array}$ & .728 & $.975 *$ & .533 & .124 & 1 & $949^{\circ}$ & $965^{\circ}$ & 334 & 367 & .396 \\
\hline & 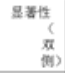 & .026 & .000 & .139 & .791 & & .000 & .000 & 379 & 331 & .291 \\
\hline & $\mathrm{N}$ & 9 & 9 & 9 & 9 & 9 & 9 & 9 & 9 & 9 & 9 \\
\hline \multirow{3}{*}{ 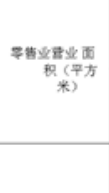 } & $\begin{array}{r}\text { Pearson } \\
\text { 相 } \\
\text { 芙 } \\
\text { 年 }\end{array}$ & .843 & $941 *$ & .377 & .151 & .949** & 1 & $982^{*}$ & 483 & 523 & .534 \\
\hline & 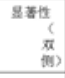 & .004 & .000 & .317 & .698 & .000 & & .000 & .188 & .149 & .138 \\
\hline & $\mathrm{N}$ & 9 & 9 & 9 & 9 & 9 & 9 & 9 & 9 & 9 & 9 \\
\hline \multirow{3}{*}{ 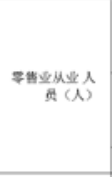 } & $\begin{array}{r}\text { Pearson } \\
\text { 相 } \\
\text { 鉎 } \\
\text { 年 }\end{array}$ & .759 & $964 * *$ & $.4 \%$ & .168 & $965 *$ & $982 *$ & 1 & .465 & 530 & .542 \\
\hline & 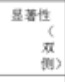 & .018 & .000 & .174 & .665 & .000 & .000 & & .207 & .151 & .132 \\
\hline & $\mathrm{N}$ & 9 & 9 & 9 & 9 & 9 & 9 & 9 & 9 & 9 & 9 \\
\hline \multirow{3}{*}{ 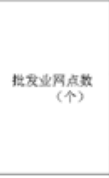 } & 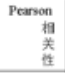 & .687 & 386 & .168 & .538 & 334 & 483 & .465 & 1 & $98 s^{* *}$ & $.981 *$ \\
\hline & 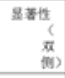 & .941 & 304 & .666 & .135 & .379 & .188 & .207 & & .000 & .000 \\
\hline & $\mathrm{N}$ & 9 & 9 & 9 & 9 & 9 & 9 & 9 & 9 & 9 & 9 \\
\hline \multirow{3}{*}{ 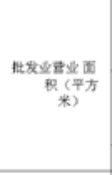 } & $\begin{array}{r}\text { Pearson } \\
\text { 相 } \\
\text { 关 } \\
\text { 徃 } \\
\end{array}$ & .674 & .428 & .185 & .488 & .367 & 523 & .520 & $98 *$ & 1 & $99 \cdot=$ \\
\hline & 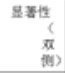 & .046 & .251 & .633 & 183 & .331 & .149 & .151 & .000 & & .000 \\
\hline & $\mathrm{N}$ & 9 & 9 & 9 & 9 & 9 & 9 & 9 & 9 & 9 & 9 \\
\hline \multirow{3}{*}{ 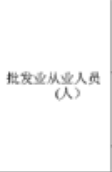 } & $\begin{array}{r}\text { Pearson } \\
\text { 相 } \\
\text { 堆 }\end{array}$ & .680 & 458 & .270 & .522 & 396 & .54 & .542 & $981 *$ & $991 *$ & 1 \\
\hline & 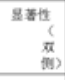 & .044 & .215 & $A 82$ & .149 & .291 & .138 & .132 & .000 & .000 & \\
\hline & $\mathrm{N}$ & 9 & 9 & 9 & 9 & 9 & 9 & 9 & 9 & 9 & 9 \\
\hline
\end{tabular}

*. 在 0.05 水平 (双侧) 上显著相关。 **. 在. 01 水平 (双侧) 上显著相关。

根据上表, 全县人口数量与县城商业网点个数总量在 0.05 水平上存在显著相关; 全县人口数量与县城商业网点 面积总量和从业人员数量不存在相关关系。全县人口数量 与县城零售商业网点个数总量在 0.05 水平上存在显著相 
关; 全县人口数量与县城零售商业网点面积总量在 0.01 水 平上存在显著相关; 全县人口数量与县城零售商业网点从 业人数在 0.05 水平上存在显著相关。全县人口数量与批发 业网点数量、批发业营业面积和批发业从业人员数, 在 0.05 水平上存在显著相关。

根据上表, 县城商业网点总数与零售业网点数、零售 业营业面积、零售业从业人员数, 在 0.01 水平上存在显著 相关; 而县城商业网点总面积与零售业网点数、零售业营 业面积、零售业从业人员数不存在相关关系。
4.2 县级社会消费品零售总额指标与商业网点相关指标关 系分析

通过 SPSS20.0 软件对全县人口和商业网点总数、网点 总面积、从业人员数、零售业网点个数、零售营业面积、 零售从业人员数、批发网点数、批发营业面积、批发从业 人员数指标进行 Pearson 双相关分析, 得到如下运行结果。

表2 社会消费品零售总额指标与商业网点指标相关分析结果表

\begin{tabular}{|c|c|c|c|c|c|c|c|c|}
\hline & $\begin{array}{c}\text { 社会消费品零 } \\
\text { 售总额 }\end{array}$ & $\begin{array}{c}\text { 商业网点 } \\
\text { 总数 }\end{array}$ & $\begin{array}{c}\text { 商业网点总面 } \\
\text { 积 }\end{array}$ & $\begin{array}{c}\text { 商业从业总人 } \\
\text { 员数 }\end{array}$ & $\begin{array}{c}\text { 零售业网点 } \\
\text { 数 }\end{array}$ & $\begin{array}{c}\text { 零售业营业面 } \\
\text { 积 }\end{array}$ & $\begin{array}{c}\text { 零售业从业人员 } \\
\text { 数 }\end{array}$ \\
\hline \multirow{3}{*}{$\begin{array}{l}\text { 社会消费品 } \\
\text { 零售总额 }\end{array}$} & Pearson 相关性 & 1 & $.760 *$ & .047 & -.081 & $.777 *$ & $.853 * *$ & $.785 *$ \\
\hline & 显著性（双侧） & & .018 & .904 & .835 & .014 & .003 & .012 \\
\hline & $\mathrm{N}$ & 9 & 9 & 9 & 9 & 9 & 9 & 9 \\
\hline \multirow{3}{*}{$\begin{array}{c}\text { 商业网点总 } \\
\text { 数 }\end{array}$} & Pearson 相关性 & $.760 *$ & 1 & .472 & .096 & $.975 * *$ & $.941 * *$ & $.964 * *$ \\
\hline & 显著性（双侧） & .018 & & .199 & .807 & .000 & .000 & .000 \\
\hline & $\mathrm{N}$ & 9 & 9 & 9 & 9 & 9 & 9 & 9 \\
\hline \multirow{3}{*}{$\begin{array}{c}\text { 商业网点总 } \\
\text { 面积 }\end{array}$} & Pearson 相关性 & .047 & .472 & 1 & .602 & .533 & .377 & .496 \\
\hline & 显著性（双侧） & .904 & .199 & & .087 & .139 & 317 & .174 \\
\hline & $\mathrm{N}$ & 9 & 9 & 9 & 9 & 9 & 9 & 9 \\
\hline \multirow{3}{*}{$\begin{array}{c}\text { 商业从业总 } \\
\text { 人员数 }\end{array}$} & Pearson 相关性 & -.081 & .096 & .602 & 1 & .124 & .151 & .168 \\
\hline & 显著性（双侧） & .835 & .807 & .087 & & .751 & 698 & .665 \\
\hline & $\mathrm{N}$ & 9 & 9 & 9 & 9 & 9 & 9 & 9 \\
\hline \multirow{3}{*}{$\begin{array}{c}\text { 零售业网点 } \\
\text { 数 }\end{array}$} & Pearson 相关性 & $.777 *$ & $.975 * *$ & .533 & .124 & 1 & $.949 * *$ & $.965 * *$ \\
\hline & 显著性（双侧） & .014 & .000 & .139 & .751 & & .000 & .000 \\
\hline & $\mathrm{N}$ & 9 & 9 & 9 & 9 & 9 & 9 & 9 \\
\hline \multirow{3}{*}{$\begin{array}{c}\text { 零售业营业 } \\
\text { 面积 }\end{array}$} & Pearson 相关性 & $.853 * *$ & $.941 * *$ & .377 & .151 & $.949 * *$ & 1 & $982 * *$ \\
\hline & 显著性（双侧） & .003 & .000 & .317 & .698 & .000 & & .000 \\
\hline & $\mathrm{N}$ & 9 & 9 & 9 & 9 & 9 & 9 & 9 \\
\hline \multirow{3}{*}{$\begin{array}{c}\text { 零售业从业 } \\
\text { 人员数 }\end{array}$} & Pearson 相关性 & $.785 *$ & $.964 * *$ & .496 & .168 & $.965 * *$ & $.982 * *$ & 1 \\
\hline & 显著性（双侧） & .012 & .000 & .174 & .665 & .000 & .000 & \\
\hline & $\mathrm{N}$ & 9 & 9 & 9 & 9 & 9 & 9 & 9 \\
\hline
\end{tabular}

*. 在 0.05 水平 (双侧) 上显著相关。

**. 在. 01 水平 (双侧) 上显著相关。 
社会消费品零售总额与商业零售网点数量, 在 0.05 水 平上存在显著相关, 而与商业网点面积和商业从业人员数 不存在相关关系。社会消费品零售总额与县城零售商业网 点个数总量在 0.05 水平上存在显著相关; 社会消费品零售 总额与县城零售商业网点面积总量在 0.01 水平上存在显著 相关; 全县人口数量与县城零售商业网点从业人数在 0.05 水平上存在显著相关。

\section{5.研究结论}

5.1 县级城市商业网点数量与该县域人口数量存在相 关关系, 初步证实县级城市商业网点服务功能不仅局限于 县级城市人口消费需求。在表 1 中, 县级城市商业网点中 批发业网点, 无论在数量、面积和从业人员数量都与县域 人口数量存在一定的相关性。

5.2 社会消费品零售总额与商业零售网点数量、面积 和从业人员数量间都存在相关性, 其之间是否存在定量关 系, 还需做进一步的分析研究。

5.3 县级城市商业网点数量与县域人口数量、社会消 费品零售总额在 0.05 水平上都存在显著相关; 而县级城市 商业网点营业面积、从业人员数量与县域人口数量、社会 消费品零售总额不存在显著相关, 初步证实商业业态数量 结构与社会消费品零售总额有关。

5.4 县级城市商业网点数量与县级城市零售业网点数 量、面积和从业人员数量存在相关关系; 县级城市零售业 网点数量、零售业网点营业面积和零售业从业人员数量存 在显著相关关系, 需进一步分析研究。

\section{参考文献(References)}

[1] Jirui, Yang, "The urban system mode choice of The large-scale development of the western region: giving priority to the development of western cities," Decision Advisory Newsletters, Jan.2001, PP. 9-13

[2] Wu Di, Pang Xiaoyu. "The Introduction to the influence of zhou city and Linzi to the Chinese early capital city planning theory" Linzi and the pre-qin ancient academic seminar, Chinese ancient capital society , 2009

[3] The city planning theory and practice during the period of planned economy system _ the construction engineering education network. http://www.jianshe99.com/lunwen/jianzhuguihua/ya150401935 1.shtml

[4] Li Hao,"Thinking about the development history of urban planning in new China," Planners, Sept.2011, PP.102 -107

[5] Zhu Xia, Hu Jianfeng, "The Confusion between fish and fish -a discussion on the modern urban planning methodology,'The third "Twenty-first Century urban development" International Conference, 2009

[6] Zhang Shiyin, "1\% urbanization level measurement and the Present situation research,"Scientific and technological information development and economy,"Feb.2005, PP.155

[7] Liu Xingyuan, "The Discussion on the layout of urban commercial network planning,'Journal of Beijing Technology and Business University (SOCIAL SCIENCE EDITION), April 2007, PP. 6-9.

[8] Fang Yuanping, Yan Xiaopei, Bi Doudou, "The research review on the commercial city location in China Since 1980,'Tropical geography, May 2007, PP. $435-440$ 